\title{
Management Information Systems Research Networks: Creating and Sharing Diverse Knowledge
}

\author{
Jyun-Cheng Wang \\ Institute of Service Science \\ National Tsing Hua University \\ 101, Sec.2, Kuang-Fu Rd. \\ Hsinchu, Taiwan 30013, R.C.C. \\ jcwang@mx.nthu.edu.tw \\ Gary Klein \\ College of Business Administration \\ University of Colorado, Colorado Springs \\ P.O. Box 7150 Colorado Springs, CO 80933-7150 \\ gklein@uccs.edu \\ James J. Jiang \\ Department of Management Information Systems \\ University of Central Florida \\ Orlando, FL 32816-1400 \\ jiiang@bus.ucf.edu \\ Paul Cheney \\ Department of Management Information Systems \\ University of Central Florida \\ Orlando, FL 32816-1400 \\ pcheney@bus.ucf.edu
}

\begin{abstract}
Certain social science fields have studied their knowledge sharing ability by examining social networks of authorships. The main point is to determine if the discipline has grown in a fashion that encourages effective sharing of diverse knowledge and the creation of new knowledge from the different subgenres that inhabit their field. Researchers in Management Information Systems have shown a great deal of concern for how their discipline has grown. Many fear a form of fragmentation due to a lack of communication across subgenres. Others are concerned that the discipline is methodologically bound, theories do not disseminate rapidly, or ideas cannot permeate tight knit clusters. We apply social network analysis to examine whether or not ideas can be transferred rapidly or created effectively via established authorship patterns that avoid the concerns. We find that networks are in place that are effective for knowledge sharing, but the field can still make strides in building networks that enable combining diverse ideas into new ideas.
\end{abstract}

Keywords: MIS Research, collaboration, social network analysis, knowledge diversity, Knowledge sharing, Knowledge creation. 


\section{Introduction}

The discipline of Management Information Systems (MIS) is characterized by a diverse body of knowledge as distinguished by the published research in the field (Hirscheim and Klein, 2003; Robey, 1996). This is manifested in a diversity of problems addressed, a diversity of theoretical foundations, a diversity of subgenres, and a diversity of research methodologies (Benbasat and Weber, 1996; Oh et al., 2006). New journals, new conferences, new departments, and new IS programs are indicators that new specialties and research communities in MIS have emerged. Regardless of whether diversity is considered a blessing or a crisis, it is widely accepted as a defining characteristic of the field (Benbasat and Zmud, 2003; Cooper, 1988; King and Lyytinen, 2003; Markus, 1997; Mingers and Stowell, 1997; Orlikowski and Baroudi, 1991).

This breadth of background and contributions does lead to possible problems, however, in the creation of new ideas and the sharing of research results to the entire community (Hirschheim and Klein, 2003). The unique specialties that exist in the field may not effectively share work across natural boundaries (Oh et al., 2006). In addition, unless some mechanism exists to connect the diverse specialties, the creation of new ideas may be stifled (Fleming and Marx, 2006). Effective networks that foster collaboration and communication, on the other hand, enable innovation and the sharing of information (Inkpen and Tsang, 2005; Moody, 2004). The question becomes what is the state of the collaborative networks in the MIS field. Is the discipline in a state of crisis as suggested by some, or are effective internal networks in place? In this paper, we examine collaboration networks in the IS literature to determine potential strengths and weaknesses in the field. We limit ourselves strictly to the internal network of researchers and relegate external networks outside the community of researchers to future studies.

\section{MIS Diversity and Collaborative Networks}

From a knowledge perspective, diversity is an abundance of ideas that represent different interests, values, and backgrounds. The achievement of diversity is important in the creation of new knowledge (Fleming and Marx, 2006). However, the dissemination of new knowledge is essential in its application to further goals (Nonaka and Takeuchi, 1995). In this case, diversity may then be a block in the sharing of knowledge since communication structures are not always evident between different interest groups or subgenres (Oh, et al., 2006; Reagans and McEvily, 2003).

\section{The Issue of Diversity in MIS}

Pluralism relates to a diversity of ideas, perspectives, research approaches, and paradigms. The advantages of diversity for an academic discipline such as MIS include (1) expanding the foundation upon which knowledge claims are based, (2) attracting good people to the field, (3) fostering knowledge creativity, and (4) advancing the principle of academic freedom (Robey, 1996). Unfortunately, diversity has its disadvantages as researchers in different subgenres appear to work on disjoint or non-pertinent topics without much cross-communication and collaboration (Bjorn-Andersen, 1984; Huber, 1983). This leads to a distinct difference between pluralism and fragmentation (Hirschheim and Klein, 2003).

Fragmentation means there is insufficient communication between the different communities such that no shared knowledge exists, where individuals work in their own sub-communities without reference to others. Two possible disconnects are involved in fragmentation, each leading to a perceived crisis in the field: 1) an internal disconnect communication gaps between IS researchers and other IS researchers, and (2) an external disconnect - communication gaps between IS researchers and other IS stakeholders such as practitioners. In this study, we 
attempt to examine the internal disconnect issue by examining co-authorship networks in the major IS journals. If internal fragmentation exists, it should show up as evidence in the network structures exhibited in the MIS research journals.

Collaborative structures represent social networks of researchers. If researchers in a sub-group exchange ideas, research questions, methods, and implicit rules for evaluating evidence with their collaborators, then this social network will generate consensus and communications among the individuals in the sub-group. These network structures are known to impact knowledge transfer and knowledge creation (Cross et al., 2001; Oh et al., 2006; Poell and Van der Krogt, 2003; Reagans and McEvily, 2003). Fragmented structures will not allow for communication of new ideas because links to span the diverse knowledge will not exist and even common interest clusters could suffer from internal communication inadequacies.

Desired knowledge exchange in networkbased models emphasizes the importance of two elements that seem contradictory: cohesion and breadth of connections. Cohesion refers to the extent to which a relationship is surrounded by strong thirdparty connections. The breadth of connections refers to spanning institutional, genre, organizational, or social boundaries. Although both network patterns have been linked to the flow of information, they are often viewed as being in opposition. Nevertheless, some researchers claim an optimal network combines elements of cohesion and breadth of connections (Reagans and Zuckerman, 2001; Burt, 2002; Garguilo and Rus, 2002). A fragmented network would not display either property.

If these desired elements are lacking, the assertion "we believe that fragmentation is a root cause of the field's potential crisis" (Hirschheim and Klein, 2003) is likely borne out. This concern is part of a continued debate on how much local autonomy IS researchers should have to formulate research problems and standards for conducting research and evaluating research results (Alter, 2001; Backhouse et al., 1991; Banville and Landry, 1989; Benbasat, 1989; Benbasat and Zmud, 1999; Cash and Lawarence, 1989; Checkland and Howell, 1998; Culnan, 1986; Culnan, 1987; Currie and Galliers, 1999; Farhoomand, 1987; Galliers, 1992; Grover et al., 2006; Hirschheim et al., 1995; Ives et al., 1980; Keen, 1980; Klein et al., 2006; Klein and Myers, 1999; Kraemer, 1991; Landry and Banville, 1992; Lee et al., 1997; Mingers and Stowell, 1997; Mumford et al., 1985; Nissen et al., 1991; Wade et al., 2006; Westin et al., 1996).

\section{MIS as a Cumulative Research Discipline}

Studies on the state of MIS as a discipline often employ citation analysis and classification approaches. Many of these cite the diversity of the field as being problematic while others call for more diversity. As early as 1987, Culnan developed an intellectual mapping of MIS based on a citation analysis for the 1972 to 1982 period. Culnan indicated significant progress toward a cumulative research tradition. Recently, Grover et al. (2006) applied citation analysis to research the evolution and state of information systems within a constellation of reference disciplines. They thought that the movement of IS towards building a cumulative tradition, and informing work in other disciplines as positive. Similar conclusions are drawn by Katerattanakul et al. (2006). However, a different perspective is offered by Wade et al. (2006). They use citation analysis to find that the IS field has left a modest imprint on other sub-fields of management. Based on this evidence, they conclude that IS is not approaching a reference discipline.

Categorization studies have discovered a number of patterns, yet draw very distinctive conclusions based on their analyses. In 1992, Alavi and Carlson reviewed 908 MIS articles in eight core journals published between 1968 and 1988 and classified three 
Management Information Systems Research Networks/Wang et al.

popular research topics including IS management, information systems characteristics, and development of IS. Mingers (2001) looked at research methods and found a number of approaches are taken but that more studies need to apply multiple methods to add to the quality of the work produced. Prasad and Tata (2005), based upon articles published in 28 IS journals from 1990 to 1999 , classified the key IS teamsrelated research topics into decision making, decision support systems, human factors, intra-organization systems, project management, telecommunications, and software.

One valuable schema that significantly added to the identity of the MIS field is the work of Barki et al. $(1988,1993)$. The result here was key words to classify the historical evolution of the field. Similarly, using submitted manuscripts, Swanson and Ramiler (1993) categorized the main research questions addressed in the MIS fields and attempted to uncover the interacting relationships among these IS disciplines. Vessey et al. (2002) analyzed the nature of the MIS research diversity issue by investigating key research dimensions that include complementary disciplines. Their analysis provided a framework for comprehending and appreciating the scale and scope of research diversity in MIS and related fields.

Even focus and theory present difficulties in establishing MIS as a unique field. Diversity of interests may be part of a problem of focus on the IT artifact in MIS research (Orlikowski and lacono, 2001). Their review indicates that MIS researchers attack problems from the context or dependent variable view and do not place enough significance on the theory of the IT artifact. A similar argument is pushed in a study that reviews the diversity of theories applied in MIS research. Barkhi and Sheetz (2001) identify 111 theories applied in 141 MIS research papers between 1994 and 1998. Their concern is that the discipline is not reaching any consensus on underlying theories.
Despite the differences in their analytical orientations and objectives, both citation and classification studies provide a useful framework for understanding different aspects of MIS research, including the subdisciplines in the IS field, main IS reference disciplines, evolution of MIS field, and diversity of MIS research. Much of the development, however, depends on the coauthorship relations that exist within the field. Little is known about co-authorship patterns, in the MIS research community. A beginning to this understanding was made by Oh et al. (2006), who indicate researchers in four reference disciplines have mixed records of collaboration across subgenres. We extend the paths taken to examine the state of the discipline and consider whether networks of authorship indicate problems of disconnects within the field or if sufficient linkages exist to promote effective sharing of knowledge. As such, our perspective is unique in that we do not consider strictly the output of the discipline; we examine the networks indicted in the output. Social network analysis (SNA) reveals patterns of connections and collaboration among MIS authors.

\section{Knowledge Sharing and Creation in Small World Networks}

Fleming and Marx (2006) employ a caveman example to describe social structures known as small world networks. A small world network is characterized by unique clusters that are dense and bounded, with some designated authority for communicating across clusters. Consider the caveman, bound by the constraints of their environment, living closely to many others in the same system of caves within easy walking distance. Ideas are freely exchanged within this cluster and are rapidly disseminated through the tight ties that bind the individuals together for survival. Here, one expects a dense network owing to frequent interaction among those in extremely close proximity.

However, some cavemen leave the cave on exploitations. As these explorers associate with members from other caves, they will pick 
up new ideas and techniques. This crossfertilization of ideas adds to creativity; is brought back to the individual caves and disseminated within the smaller clusters. They dramatically reduce social distance because each cave member can now reach a different cave member via a few indirect links. Individuals who bridge the cave societies create a small world by extending the reach of their dense clusters to other societies. Can the MIS field be characterized as dense clusters of subgenres bridged by some explorers in the field?

The internal density and interconnectedness of a social network should have a positive effect on knowledge transfer, primarily through influencing the willingness of individuals to devote time and effort to assisting others (Burt, 2002). Individuals who work in such a homogenous network are surrounded by contacts that view issues in similar ways. There is no need to consider multiple perspectives because most network members see the world in the same way. Common languages and terminology also facilitate communication and knowledge transfer inside the group. For these same reasons, it is difficult for these people to communicate what they know to outsiders. Ideas are rapidly disseminated in this structure but the diversity for knowledge creation may not be present. Some mechanism must be present to span these boundaries and transfer knowledge from and to other groups (Tushman, 1977). So dense clusters serve to effectively transfer ideas within its membership, but lack the ability to reach out to newer ideas.

The transfer of knowledge across boundaries, within or outside the organization, has been shown to improve performance (Epple et al., 1991). To transfer knowledge successfully across a boundary, the source has to frame what he/she knows in a language that the recipient can understand, requiring that those exploring outside their tight clusters must develop common language and terminology with his counterparts. When the source does not or cannot frame knowledge in a language that the recipient can understand, comprehending that knowledge can be difficult and costly for the recipient (Borgatti and Cross, 2003).

Individuals within networks spanning several clusters should find it easier to transfer knowledge because the behaviors that ease knowledge transfer are part of their everyday network activity. In addition, this broad reach across dense clusters allows the intermingling of ideas and the creation of new ones (Burt, 2002). Authors accustomed to interacting with contacts from diverse groups of practice are presented with a greater opportunity to learn how to convey complex ideas than are individuals limited to interactions within a single body of knowledge (Reagans and McEvily, 2003). People connected to multiple bodies of knowledge are exposed to more worldviews and more over, they are more likely to recognize the need for discussion. And they are more likely to frame their communication in a language that a contact can understand (Padgett and Ansell, 1993).

The process of attachment by individuals to a network also exposes certain traits about the network structure. As new entrants enter the network, high-status scientists are often attractive collaborators since one's own status is a function of the status of those to whom one is connected (Bonacich, 1987; Gould, 2002). It implies that individuals will seek to work with high-status researchers, and this process will be self-reinforcing, which would lead to a "the rich get richer" phenomenon. This is called preferential attachment in Barabasi et al. (1999), and the network is characterized by having a scalefree power-low distribution, such that the probability of having $\mathrm{k}$ partners is distributed as $\mathrm{k}^{-\mathrm{r}}(\mathrm{k}$ is a constant), and we can thus use a log-log distribution to view whether this preferential attachment exists within clusters.

\section{Social Network Propositions in MIS Research}

Social networks add a conceptual formality to 
Management Information Systems Research Networks/Wang et al.

the collaborative relationships in research networks. A social network is a set of actors (authors) that have relationships (coauthorships) with one another. Networks can have few or many actors, and one or more kinds of relations between pairs of actors. To study a social network, a rigorous description of a pattern of social relationships is a necessary starting point for analysis. All of the relationships between each pair of actors are examined (Borgatti, 1998; Hanneman, 1998; Wellman, 1996).

The vision of a theory and genre fractured IS suggests strong subgenres with little interchange, as analyses of citations and networks has suggested (Nerur et al., 2005; Oh et al., 2006). If substantive boundaries mean that people are not interested in diversity of work, then people will turn to fellow specialists as collaborators. Researchers will be trained within particular specialties and build distinct communities surrounding particular topics. This implies dense clusters, but not much connection across the clusters. Isolated research clusters will likely inhibit broad theoretical integration, since theory will progress largely within distinct research groups. The size of the largest component will be limited by the isolation of the clusters with no outreach to other clusters. Within clusters, however, dissemination of ideas will be rapid and work will be productive. If MIS research collaborations fit this model, then we propose that

Proposition 1: collaboration networks in MIS have limited size to the largest component Proposition 2: collaboration networks in MIS are dense

There are collaborators with more links than others and are the most reputed authors in a field. Crane (1972) found that a small number of very prominent scientists in a collaboration network and that most others were connected to the rest of the community through these highly active individuals. This central position helps explain why core scientists are able to rapidly diffuse their ideas through the entire community. Coauthors will attach to the network affiliated with these prominent performers in a preferential attachment process, meaning that an authors' chance of being connected is positively correlated with the links the author already had. We term these highly connected, prominent performers as star collaborators. In MIS, a small number of researchers receive disproportionate recognition, indicating a good likelihood that potential star collaborators exist (Huang and Hsu, 2005; Oh et al., 2006).

For a somewhat different concept, there is another type of collaborator called a gatekeeper who plays a pivotal role of bridging two clusters. Gatekeepers represent an effective form of outreach from one dense cluster to another. A lack of gatekeepers would require connections to other disciplines by many members of the social network. However, these collaborators also have the potential to bridge the gaps across clusters by working with other gatekeepers. Some of this is reflected in the high level of structural cohesion of the networks, but the impact of the gatekeepers is to interact with gatekeepers in the other clusters to foster an exchange of new ideas and actively promote knowledge creation. If connections do not exist across clusters, then fragmentation exists as suggested by Hirscheim and Klein (2003). Gatekeepers can be anyone within a cluster, but star collaborators are often looked to for leadership in the direction of the body of work and should have attributes of a gatekeeper. Based on the previously discussed works of others who have studied the discipline, these connections are not expected to permeate the networks. Based on this information, we propose:

Proposition 3: MIS authors attach to highly connected authors in a preferential process Proposition 4: MIS star collaborators do not serve as gatekeepers for their immediate social clusters. 


\section{Data and Methods}

There are an increasing number of papers using SNA to discuss patterns of development in academic communities. For example, Powell et al. (2005) used a social network method to analyze network dynamics and field evolution of interorganizational collaboration in the Life Sciences. Moreover, Moody (2004) used indicators of social networks to observe the structure of a social science collaboration network. Newman (2001, 2004) also used a social network method to analyze the structure of scientific collaboration networks. These papers research patterns of community in creative fields. This study attempts to explore the community of MIS, and thus borrows methods from the SNA literature. Several metrics and graphics from social network research provide means of network characterization (Brandes et al., 2001; Moody et al., 2005).

\section{Data Collection}

Previous studies (Gillenson and Stutz, 1991; Katerattanakul et al., 2003; Lowry et al., 2004; Peffers and Ya, 2003; Saunders, 2005c) have identified a wide range of highly regarded journals in the MIS field. Among them, seven journals were selected for this study. Each journal was examined individually to reveal the collaboration network associated with a journal. Co-author information from six of the seven journals is taken from ProQuest. For MIS Quarterly, ISR, and JMIS, we also consult another premium research database, EBSCOhost BSP, to get complete coverage of journal information. We extract co-author data from the database matching each journal title to construct the collaboration network. The one exception to these sources is the articles in JAIS, which are taken directly from the journal's official website. The journal titles, years of first issue, and respective data collection periods are listed in Table 1 .

\begin{tabular}{|l|l|l|l|}
\hline \multicolumn{3}{|c|}{ Table 1 Journal Titles and Respective Data Collection Period } \\
\hline Journal Title & $\begin{array}{l}\text { First Issue } \\
\text { published }\end{array}$ & $\begin{array}{l}\text { Data } \\
\text { Collection } \\
\text { Period }\end{array}$ & Data Source \\
\hline Decision Sciences & 1970 & $1978-2006$ & ProQuest \\
\hline MIS Quarterly & 1977 & $1977-2006$ & $\begin{array}{l}\text { ProQuest and } \\
\text { EBSCOhost BSP }\end{array}$ \\
\hline ISR & 1990 & $1990-2006$ & $\begin{array}{l}\text { ProQuest and } \\
\text { EBSCOhost BSP }\end{array}$ \\
\hline JMIS & 1984 & $1984-2006$ & $\begin{array}{l}\text { ProQuest and } \\
\text { EBSCOhost BSP }\end{array}$ \\
\hline $\begin{array}{l}\text { Information \& } \\
\text { Management }\end{array}$ & 1978 & $1981-2006$ & ProQuest \\
\hline DSS & 1985 & $1985-2006$ & ProQuest \\
\hline JAIS & 2000 & $2000-2006$ & JAIS website \\
\hline
\end{tabular}

\section{Network Construction}

In constructing a collaboration network, we adopt the approach used in Moody (2004). Each node represents one author. An edge is established between two nodes when two authors publish a paper together, regardless of the number of times they have co-authored, thus leading to a dichotomous network in the sense that the value associated with a link between two nodes is either zero, for no coauthorship, or one, for at least one time of coauthorship. In the case when more than two people collaborate on a paper, dyadic links are established for all pairs of co-authors. Example translations are shown in Figure 1 (adapted from Moody, 2004). 
(a) Publication data

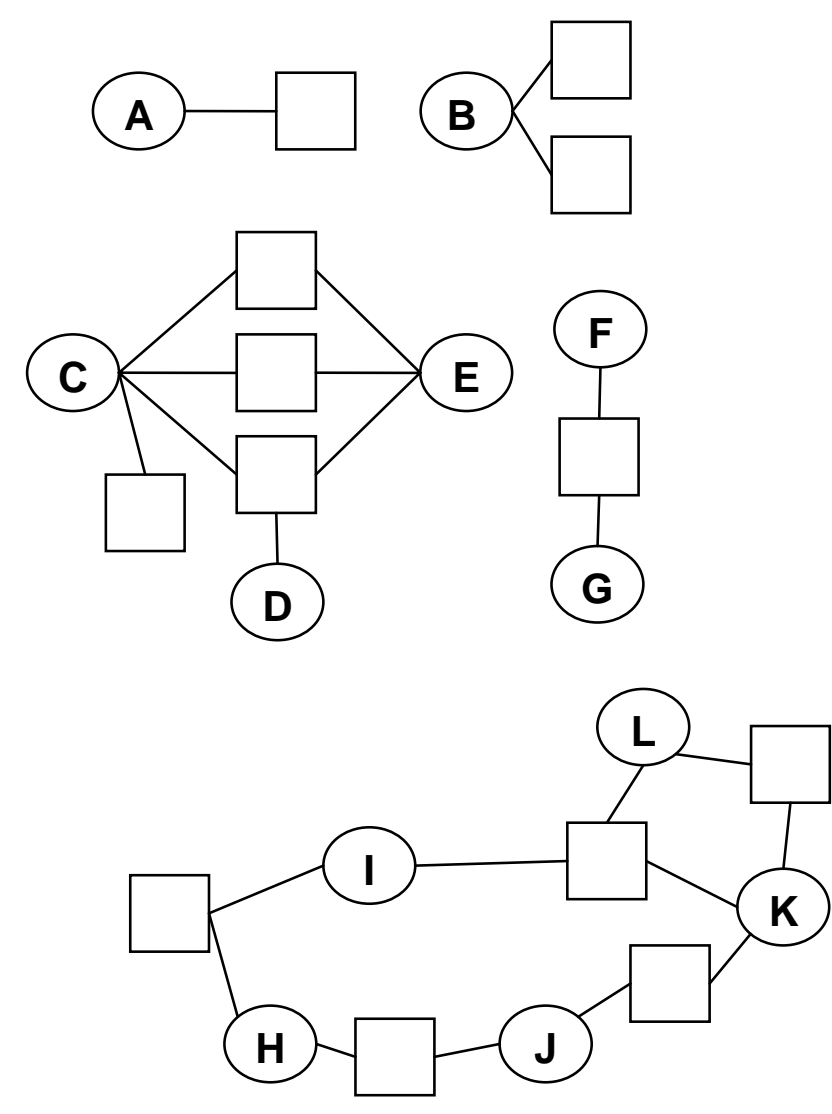

(b) Collaboration network
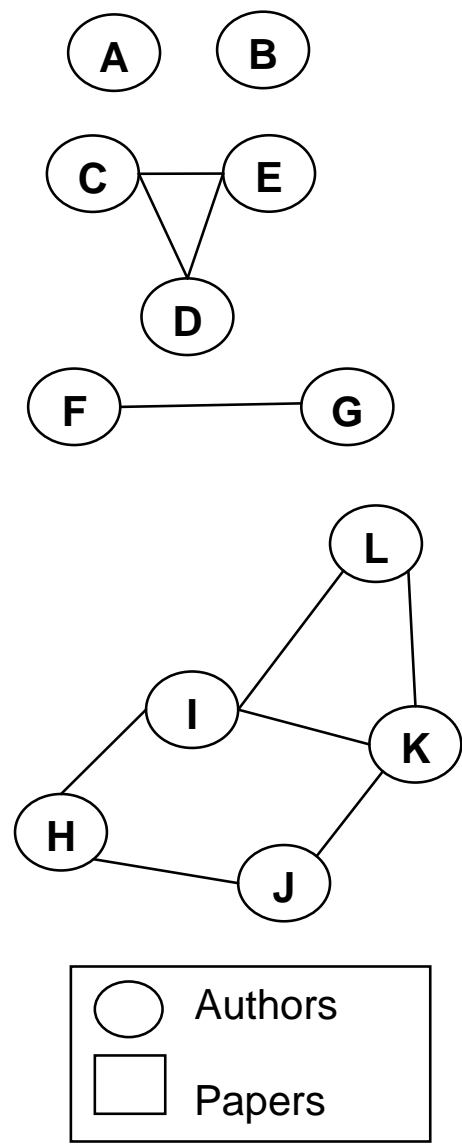

\section{Figure 1 From Publication Data to Collaboration Network}

\section{Indicators}

Four indicators were adopted in this study including (1) structural cohesion, (2) small world properties, (3) preferential attachment, and (4) gatekeeper connections. "Structural cohesion" identifies the largest component within a network, or how far knowledge readily spreads. Structural cohesion will represent the relations needed to examine proposition 1. Small world properties show the interconnectedness, or the paths that exist to transfer knowledge within a network. Small world properties measure the conditions of proposition 2. Preferential attachment highlights the presence of preferred authors for collaboration and serve as the indicator of proposition 3. Gatekeeper connections consider the interactions among small clusters made by the identified highly connected collaborators. This is a limited view of gatekeeper connections relying on the star collaborators to be the primary connections, but will serve as an indicator for proposition 4. 


\section{Structural Cohesion}

Structural cohesion calculates the largest component in a network representation (Reagans and McEvily, 2003). The size of the largest component in a network is the number of vertices that connect together. An increase in the size of the largest connected component contributes to the measure of structural cohesion. To determine the level of structural cohesion, the size of the largest component in the observed network is compared against that of a random network. This contrasting random network is constructed by randomly assigning collaboration relationships among the same number of authors. The ratio between the observed network and the randomly constructed network is used as the level of structural cohesion. Reagans and McEvily (2003) have shown that high levels of structural cohesion have a positive effect on knowledge transfer. Knowledge creation is enhanced by the diversity of the contacts (Nonaka and Takeuchi, 1995). A small value for structural cohesion will support proposition 1.

\section{Small World Properties}

In networks that have small world properties, the average distance (number of links) between nodes is small relative to the total number of nodes (Watts, 1999). In addition, small world networks display a degree of clustering higher than expected for random networks (Watts and Strogatz, 1998). To test whether a network has small world network properties, we compare certain measures of the observed network against a random graph with a similar number of nodes. Two measures are commonly used here, one is the clustering coefficient, which measures local clustering by calculating the proportion of all "two-step contacts that are also directly connected" (Moody, 2004). Specifically, the clustering coefficient is defined as follows. For a vertex $\mathrm{v}$, assuming it has $\mathrm{k}$ neighbors, then there are at most $\mathrm{k}(\mathrm{k}-1) / 2$ can exist between them. Let $\mathrm{Cv}$ denote the fraction of these allowable edges that actually exist. The resulting clustering coefficient is the average of $\mathrm{Cv}$ over all $v$. The other measure is the average path length, which is the number of edges in the shortest path between two vertices, averaged over all pairs of vertices. A small-world network has a clustering coefficient that is higher than what is expected in a random network and the distances are roughly equivalent to what is expected in a random network of similar size and distribution. The values of these measures supporting a small world will also support proposition 2.

\section{Preferential Attachment}

A lack of any preference in attachment to a network would exhibit the traits of complete randomness. A phenomenon called preferential attachment is discovered for scale-free networks in which nodes tend to link to those of already having a higher number of connections (Barabasi et al., 1999; Barabasi et al., 2002). In the context of a coauthor network, a preferential attachment phenomenon shows that a high-status researcher is more likely to attract new people to collaborate. When a co-authorship network is constructed through a preferential attachment process, the distribution of number of unique coauthors would follow a power-law distribution (Barabasi et al., 1999; Moody, 2004). This distribution can be presented as a straight line when plotted on a log-log scale. Thus, to determine whether a co-authorship network depends on highly connected collaborators, we examine whether the number of unique collaborators follows a power-law distribution. A linear relation on the log-log scale would support proposition 3.

\section{Star Collaborators as Gatekeepers}

Whether or not the star collaborators within each social cluster connect to others in remaining clusters can be examined by a simple ratio of actual connections to possible connections. The ratio will range from zero to one, where one indicates a fully formed 
Management Information Systems Research Networks/Wang et al.

network. This will illustrate how many links exist to allow knowledge to flow across unique social clusters and interact to form new knowledge. In the case of highly connected collaborators, or star collaborators, the simple metric examines how well connected the gatekeepers work with others on co-authorships. A high ratio will indicate that these star collaborators are serving as gatekeepers. Should other members of a cluster be serving as gatekeepers, the clusters will still be connected and show a high value of structural cohesion.

\section{Results}

Appendix A shows the network graphs generated for each major publication using the indicated dates. To determine the structural cohesion characteristics of the MIS field as represented in these journals, the sizes of the largest component were determined as reported in Table 2, and tend to be low for most journals. Examining the graphs in the Appendix, one can see that the relationships typically cluster into isolated groups. There is no true standard of comparison for the discipline, but a comparison across journals indicates differences in structural cohesion. What is most significant is that when combining all journals, the observed size of the largest component is $59 \%$ of the size of a random network, compared with from $17 \%$ to $6 \%$ for most journals. This indicates that individual journals may represent somewhat closed structures, but the field as a whole overcomes these. Support of Proposition 1 is mixed. When looking at a limited view by journal only MISQ has reached out across the social clusters to expand the network, but this must be taken with caution since the diversity of topics and methods are likely not identical across journals (Dennis et al., 2006). Taken as a group of journals, MIS as a discipline appears to have respectable size of the largest component. Overall, proposition 1 holds within most journals, but not as an overall discipline.

\begin{tabular}{|l|c|c|c|c|c|c|c|c|}
\hline Table 2 Structural Cohesion \\
\hline & MISQ & JMIS & IM & ISR & DSS & JAIS & DS & ALL \\
\hline Nodes & 985 & 1079 & 1729 & 529 & 1954 & 177 & 615 & 5511 \\
\hline Size of largest component: & & & & & & & & \\
\hline Observed & 311 & 126 & 167 & 61 & 119 & 7 & 45 & 2338 \\
\hline Random paper assignment & 596 & 759 & 1049 & 347 & 1291 & 106 & 379 & 3962 \\
\hline Ratio of observed to random & 0.5218 & 0.166 & 0.1592 & 0.1758 & 0.0922 & 0.066 & 0.1187 & 0.5901 \\
\hline
\end{tabular}

\begin{tabular}{|l|c|c|c|c|c|c|c|c|}
\hline Table 3 Small World Properties \\
\hline & MISQ & JMIS & IM & ISR & DSS & JAIS & DS & ALL \\
\hline Nodes & 985 & 1079 & 1729 & 529 & 1954 & 177 & 615 & 5511 \\
\hline Clustering coefficient & 0.764 & 0.811 & 0.801 & 0.785 & 0.874 & 0.939 & 0.897 & 0.784 \\
\hline (Random expected) & 0.003 & 0.002 & 0.000 & 0.004 & 0.001 & 0.007 & 0.003 & 0.000 \\
\hline Average Path Length & 6.743 & 3.942 & 5.684 & 3.492 & 3.385 & 1.177 & 2.996 & 7.254 \\
\hline (Random expected) & 8.927 & 8.268 & 10.250 & 7.469 & 9.749 & 6.555 & 8.403 & 14.137 \\
\hline
\end{tabular}

In Table 3, values of clustering coefficients are given for each journal and for all the journals collectively. All coefficients are much larger than the random coefficient indicating a very dense network with many backup paths to facilitate knowledge transfer and support the notion of a small world network. The path length varies by journal, with MISQ being 
closer to the equal length expectation and others showing shorter length. This indicates a dense network as well as there are closer connections to other network members than expected. In general, the results indicate that there is a strong clustering effect in the IS community, showing support for proposition 2. Networks are dense providing for rapid dissemination of ideas within clusters, but not necessarily outside of clusters. So by itself, dense networks are desirable, but are not sufficient to promote the cross-fertilization desired.

For collaboration following a preferential attachment, the distribution of the number of coauthors that an individual has collaborated with would follow a power-law distribution and will be seen as a straight line when plotted on a log-log scale. Table 4 shows the data that will be plotted. As an example, in MISQ about $38.70 \%$ of authors have only published with one coauthor, $30.82 \%$ have published with two other co-authors, and about $14.04 \%$ have published with three co-authors. As the coauthor-count increases, the percentage drastically decreases. Figure 2 shows the loglog scale of distribution of number of coauthors. The vertical axis is the log scale of frequency, and horizontal axis is the log scale of number of coauthors (or degree, minimum value is 1). In general, the observed distributions fit a power law pattern, suggesting that the network in most journals (and all journals collectively) exhibit a gatekeeper effect. Thus, proposition 3 is supported for most journals and the field as a whole. JAIS and DSJ may not have this pattern due to a more limited number of publications (being newer journal and multidisciplinary, respectively).

Whether or not the gatekeepers function to bridge separate clusters is not answered by this information. Table 5 shows the ratios of actual connections among star collaborator to maximum possible connections. Essentially, only one journal, MISQ, has the characteristic of these potential gatekeepers reaching out across to others to allow the spread of knowledge outside small social clusters. The field as a whole shows poor performance, with the overall ratio indicating little reach. However, the number of possible gatekeepers inflates this measure, so the "all" measure is not directly comparable to any of much smaller size (cannot compare the field as a whole to the individual journal values). Still, proposition 4 is supported in this data, star collaborators do not typically reach out to peers in other clusters. However, the sizes of the clusters in the structural cohesion measure indicate that connections are made, and members not in the star category are making these connections. 


\section{Table 4. Distribution of the Number of collaborators for authors having coauthors}

\begin{tabular}{|c|c|c|c|c|c|c|c|c|c|c|c|c|c|c|c|c|c|c|c|c|c|c|c|}
\hline \multicolumn{3}{|c|}{ MISQ } & \multicolumn{3}{|c|}{ JMIS } & \multicolumn{3}{|c|}{ IM } & \multicolumn{3}{|c|}{ ISR } & \multicolumn{3}{|c|}{ DSS } & \multicolumn{3}{|c|}{ JAIS } & \multicolumn{3}{|c|}{ DS } & \multicolumn{3}{|c|}{ ALL } \\
\hline $\begin{array}{l}\text { Co. } \\
\text { No. }\end{array}$ & Freq & $\%$ & $\begin{array}{l}\text { Co. } \\
\text { No. }\end{array}$ & Freq & $\%$ & $\begin{array}{l}\text { Co. } \\
\text { No. }\end{array}$ & Freq & $\%$ & $\begin{array}{l}\text { Co. } \\
\text { No. }\end{array}$ & Freq & $\%$ & $\begin{array}{l}\text { Co. } \\
\text { No. } \\
\end{array}$ & Freq & $\%$ & $\begin{array}{l}\text { Co. } \\
\text { No. }\end{array}$ & Freq & $\%$ & $\begin{array}{l}\text { Co. } \\
\text { No. } \\
\end{array}$ & Freq & $\%$ & $\begin{array}{l}\text { Co. } \\
\text { No. }\end{array}$ & Freq & $\%$ \\
\hline 1 & 339 & 38.70 & 1 & 273 & 27.58 & 1 & 660 & 43.59 & 1 & 184 & 36.73 & 1 & 587 & 32.90 & 1 & 50 & 33.78 & 1 & 201 & 55.52 & 11 & 20 & 0.40 \\
\hline 2 & 270 & 30.82 & 2 & 357 & 36.06 & 2 & 475 & 31.37 & 2 & 162 & 32.34 & 2 & 575 & 32.23 & 2 & 51 & 34.46 & 2 & 109 & 30.11 & 12 & 13 & 0.26 \\
\hline 3 & 123 & 14.04 & 3 & 178 & 17.98 & 3 & 224 & 14.80 & 3 & 82 & 16.37 & 3 & 346 & 19.39 & 3 & 27 & 18.24 & 3 & 41 & 11.33 & 13 & 5 & 0.10 \\
\hline 4 & 57 & 6.51 & 4 & 82 & 8.28 & 4 & 74 & 4.89 & 4 & 23 & 4.59 & 4 & 179 & 10.03 & 4 & 18 & 12.16 & 4 & 8 & 2.21 & 14 & 6 & 0.12 \\
\hline 5 & 27 & 3.08 & 5 & 32 & 3.23 & 5 & 33 & 2.18 & 5 & 21 & 4.19 & 5 & 46 & 2.58 & 5 & 1 & 0.68 & 5 & 1 & 0.28 & 15 & 6 & 0.12 \\
\hline 6 & 15 & 1.71 & 6 & 18 & 1.82 & 6 & 23 & 1.52 & 6 & 9 & 1.80 & 6 & 18 & 1.01 & 6 & 1 & 0.68 & 6 & 1 & 0.28 & 16 & 9 & 0.18 \\
\hline 7 & 14 & 1.60 & 7 & 12 & 1.21 & 7 & 6 & 0.40 & 7 & 6 & 1.20 & 7 & 11 & 0.62 & & & & 8 & 1 & 0.28 & 17 & 2 & 0.04 \\
\hline 8 & 7 & 0.80 & 8 & 9 & 0.91 & 8 & 6 & 0.40 & 8 & 4 & 0.80 & 8 & 7 & 0.39 & & & & & & & 18 & 3 & 0.06 \\
\hline 9 & 4 & 0.46 & 9 & 7 & 0.71 & 9 & 6 & 0.40 & 9 & 3 & 0.60 & 9 & 3 & 0.17 & & & & & & & 19 & 0 & 0.00 \\
\hline 10 & 1 & 0.11 & 10 & 3 & 0.30 & 11 & 1 & 0.07 & 10 & 1 & 0.20 & 10 & 4 & 0.22 & & & & & & & 20 & 3 & 0.06 \\
\hline 11 & 5 & 0.57 & 11 & 1 & 0.10 & 12 & 1 & 0.07 & 11 & 2 & 0.40 & 11 & 1 & 0.06 & & & & & & & 21 & 4 & 0.08 \\
\hline 12 & 3 & 0.34 & 12 & 3 & 0.30 & 13 & 2 & 0.13 & 12 & 1 & 0.20 & 12 & 2 & 0.11 & & & & & & & 22 & 4 & 0.08 \\
\hline 13 & 1 & 0.11 & 13 & 2 & 0.20 & 16 & 1 & 0.07 & 18 & 1 & 0.20 & 13 & 1 & 0.06 & & & & & & & 23 & 2 & 0.04 \\
\hline 16 & 1 & 0.11 & 14 & 3 & 0.30 & 18 & 1 & 0.07 & 20 & 1 & 0.20 & 16 & 1 & 0.06 & & & & & & & 24 & 1 & 0.02 \\
\hline 17 & 2 & 0.23 & 15 & 1 & 0.10 & 20 & 1 & 0.07 & 27 & 1 & 0.20 & 21 & 2 & 0.11 & & & & & & & 25 & 2 & 0.04 \\
\hline 21 & 1 & 0.11 & 16 & 1 & 0.10 & & & & & & & 39 & 1 & 0.06 & & & & & & & 27 & 2 & 0.04 \\
\hline 22 & 1 & 0.11 & 18 & 1 & 0.10 & & & & & & & & & & & & & & & & 28 & 1 & 0.02 \\
\hline 24 & 1 & 0.11 & 19 & 2 & 0.20 & & & & & & & & & & & & & & & & 30 & 1 & 0.02 \\
\hline 25 & 1 & 0.11 & 27 & 2 & 0.20 & & & & & & & & & & & & & & & & 31 & 1 & 0.02 \\
\hline 26 & 1 & 0.11 & 32 & 1 & 0.10 & & & & & & & & & & & & & & & & 33 & 1 & 0.02 \\
\hline 27 & 1 & 0.11 & 35 & 1 & 0.10 & & & & & & & & & & & & & & & & 35 & 1 & 0.02 \\
\hline 41 & 1 & 0.11 & 56 & 1 & 0.10 & & & & & & & & & & & & & & & & 37 & 2 & 0.04 \\
\hline & & & & & & & & & & & & & & & & & & & & & $40+$ & 4 & 0.08 \\
\hline & & & & & & & & & & & & & & & & & & & & & $50+$ & 3 & 0.06 \\
\hline
\end{tabular}


Wang et al.: Management Information Systems Research Networks: Creating and Sh

Management Information Systems Research Networks/Wang et al.

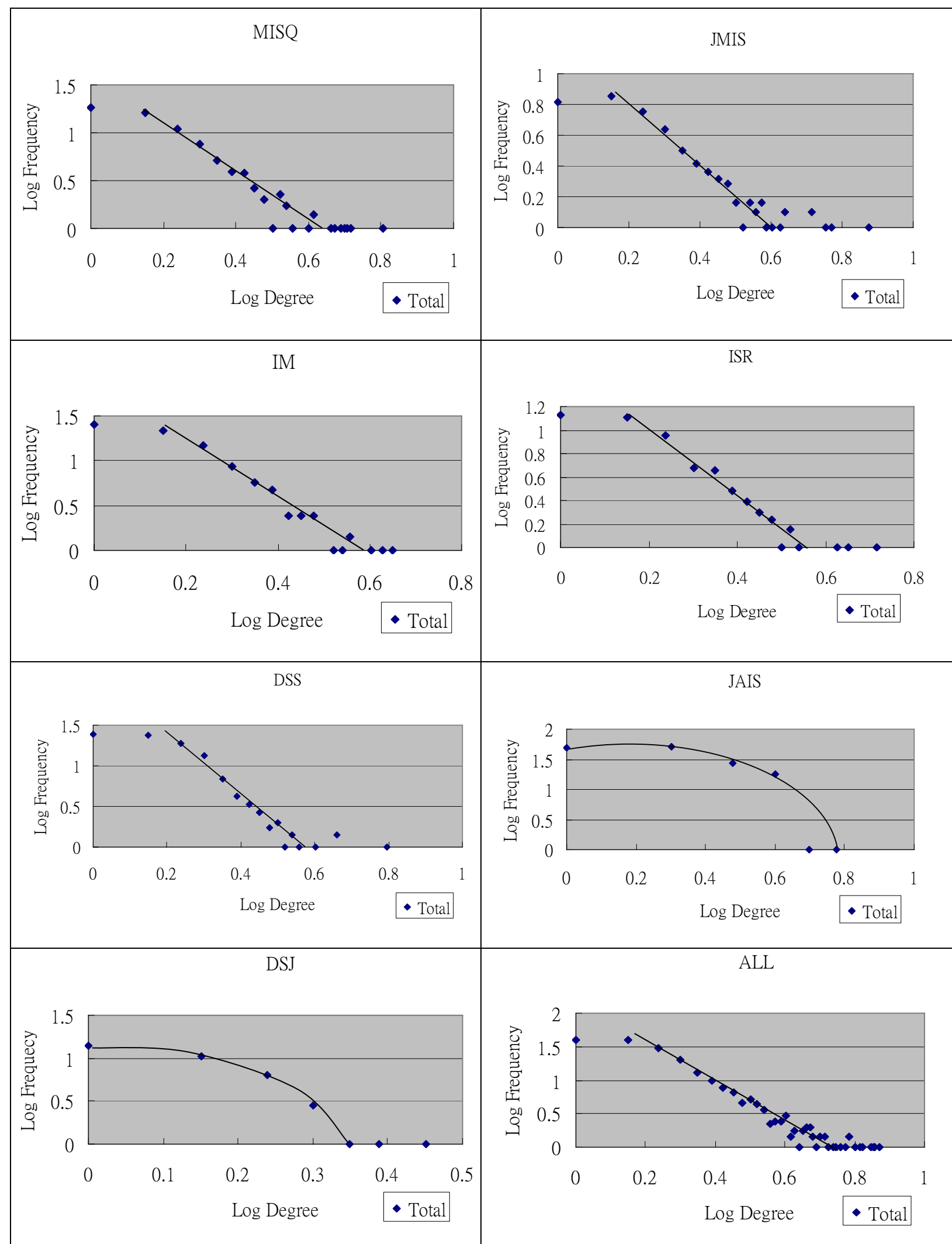

Figure 2: Collaborations 
Table 5 Gatekeeper Connections

\begin{tabular}{|l|c|c|c|c|c|c|c|c|}
\hline & MISQ & JMIS & IM & ISR & DSS & JAIS & DS & ALL \\
\hline Gatekeeper count & 14 & 13 & 19 & 14 & 15 & 20 & 11 & 87 \\
\hline Ratio actual/possible & .36 & .12 & .21 & .12 & .13 & .16 & .22 & .04 \\
\hline
\end{tabular}

\section{Discussion}

The data has shown support for a number of the propositions about the field of MIS research. A quick characterization is that the total coauthor network in MIS is tightly integrated and has fair level of structural cohesion to include other clusters in the sharing of ideas. However, the individual journals themselves typically do not follow this pattern. Additionally, star collaborators are identifiable and could serve the field by reaching out to other clusters for the exchange of diverse ideas. The results here, however, indicate that there are minimal connections among these potential gatekeepers.

The level of structural cohesion, as measured by the size of the largest component, especially within journals, may not be achieved to the desired extent due to the nature of MIS deriving from multiple reference disciplines (Oh, et al., 2006). Structural cohesion is crucial, however, because theoretical development is not linear, but instead follows a "fractal walk" through the available idea space (Daipha, 2001). Pushed by competition for status, proponents of one set of ideas attempt to vanquish another, only to find that they need to reinvent those same ideas later. This results in a constant revisiting of ideas that interests in the discipline as actors continuously loop through wide sections of the available idea space (Daipha, 2001).

However, a lack of theoretical consensus creates permeable theoretical boundaries that should make it difficult for a particular social sciences field to exclude ideas once they are introduced (Abbott, 2001). Permeability allows for cross-topic collaboration, since the same theoretical frame can be applied to multiple empirical questions. This implies that while people might specialize in techniques or approaches, these techniques and approaches are transferable across research questions. Authors with particular technical, empirical or theoretical skills will mix freely with those who have worked in different research areas, in an attempt to establish a new position by combining previous work - sharing diverse knowledge in order to create new knowledge.

From these two perspectives, a field can benefit from the lack of structural cohesion as well as suffer from a lack of a common theoretical underpinning. MISQ represents the case more where a common bond seems to exist. Given its longer history of focusing more on theoretically grounded behavioral issues, its uniformity should be expected. The other journals indicate the diversity and lack of bond that many fear. However, which leads to the best results is not yet determined. If we are to encourage thought from many base disciplines, then it will be more natural to build from among the numerous clusters. If we are to work toward a common theory that must then drive all other works, the pattern of a larger structure is more appropriate.

Where the IS field excels is in the density of its networks. Regardless of how the clusters are built, ties are distributed such that star collaborators (highly connected collaborators) in the network are not crucial for connections within clusters, and ideas are more likely to be spread by other individuals. Individuals work with the same set of local contributors and maintain multiple redundant ties with one another and engender trust (Coleman, 1988). By engendering trust, dense clustering 
encourages sharing, widespread and lateral communication. As a result of these behaviors, dense structures will greatly enhance the development of an idea and also aid the subsequent diffusion of an idea from its original creators to potential adopters. The downside to such dense clustering is that it may make seminal creativity less likely. Clustering insulates groups from new information, ideas, and opportunities. Isolated groups of researchers go stale and risk vulnerability to groupthink (Fleming and Marx, 2006). So, rapid dissemination of ideas is not problematic as the density of proposition 2 indicates. However, unless ties are made across clusters the field may indeed be fractured.

Cohesive clusters with bridging connections, however, can escape this fundamental concern of having a fractured discipline. Bridging ties counterbalance insularity by bringing in fresh and non-redundant information. The combination of this fresh information with the trust, resource sharing, and robust flow of information within clusters improves creativity in small worlds. In addition, bridging ties also enhance diffusion by providing additional connections for the transfer of ideas out of a cohesive cluster. The combination of bridging ties and clustering - small worlds - provides for easier diffusion and more new ideas to start with. As a result, researchers within small world networks will create more new ideas drawing on the diversity in the discipline and those ideas will diffuse more quickly. Since new ideas provide the basis and trigger for further new ideas, small worlds lead to a virtuous and self-reinforcing cycle of creativity and knowledge diffusion.

The first step in managing individuals in a small world is to identify the key bridging connections to the outside world -gatekeepers. Gatekeepers often enjoy deep technical respect from peers in their clusters and work closely with other gatekeepers outside their clusters. A gatekeeper often invents, communicates, and exploits his/her boundary-spanning positions to keep abreast of current developments, problems, and breakthroughs. He/she actively consumes and contributes to the literature - translating important external results for their colleagues and identifying trends, threats, and opportunities for their clusters. Gatekeepers should use their awareness and brokerage of different clusters to join disconnected individuals who have the potential for fruitful collaboration (Fleming and Marx, 2006). In the case of a networked research community, potential gatekeepers are identifiable highly connected collaborators who can serve as natural leaders within their clusters (Moody, 2004). In looking at the support for propositions 3 and 4, the discipline is strong in star collaborators, but they are not dominant in bridging the clusters.

It becomes important to consider the limitations of this study before drawing suggestions. Of foremost consideration is a lack of sound benchmarks for these measures in the management disciplines. As such, a comparative basis does not exist. In addition, networks grow over time. This is evident just in comparing the figures in the appendix associated with older journals (I\&M) to those introduced more recently (JAIS). In this fashion, expectations would have to be pegged based upon the age of the discipline, again without standards of comparison. What can be made are suggestions that would improve the numbers regardless of whether or not they are already good in comparison to those in other disciplines. A second concern is the selection of journals. Those chosen may not be the same set that others would select as being among the elite journals, and their respective ages prohibit a direct comparison. The inclusion of only one niche journal (DSS) may also slant the results providing a pattern that may be unique to those with a more limited focus.

Based on social network analysis, the MIS field has done extremely well in the building of dense clusters and in the generation of star collaborators, both of which are crucial in the sharing and creating of knowledge. Still, 
Management Information Systems Research Networks/Wang et al.

several suggestions could be made regarding the field to encourage more structural cohesion and interaction among gatekeepers. Journal policies could encourage the use of multiple reference disciplines. Reviewers could be selected both from within a cluster and from without to encourage crossfertilization and fruitful critiques (Saunders, 2005a; Saunders, 2005b). The relatively informal practice of selecting star collaborators as editorial members is sound, but only if the resulting editorial board is diverse and encouraged to actively seek new ideas, methods, and reference disciplines not adequately represented in the published pages of each journal.

Broader considerations must be made to other disciplines and other authors must be encouraged to publish across clusters and target premier journals. Valacich et al. (2006) show that about 5.5 authors per 100 faculty have published in the premier IS journals during the period of 1994 to 2003 and indicate that without substantial changes IS will continue to lag far below other business disciplines. They, along with others, suggest that the IS community should (1) increase the number of publications in the current premier journals, (2) take a broader view of what constitutes publishable work in premier IS journals and incorporate other reference disciplines, employ varying levels of analysis, use conceptual arguments, and allow pure theoretical analyses and mathematical methods - in other words publish more of the diversity that exists in the field (Dennis et al., 2006), (3) establish realistic standards for the review process (Saunders, 2006), and (4) educate colleagues about the relative differences in premier publication opportunities across disciplines.

Structural issues also exist in the academic profession as a whole. Do rewards for publishing new ideas across clusters exist in the MIS discipline? A mismatch between the objectives of knowledge creation and recognizing only a couple of premier journals exists. Dennis et al. (2006) suggest that the IS field needs to promote a third or fourth widely recognized elite journal. They additionally state that if we take the view that we are out to grow the MIS discipline we should consider opening our perspectives on the value of drastically different theories, methods, and applications. Journal boards and editors should be proactive in their outreach while maintaining quality and meeting the publication's mission. The discipline must also utilize mechanisms other than publications to expand the knowledge. Grants, conferences, and mentoring can serve crucial functions that also must show cohesion, reach, and the effective use of Gatekeepers. 


\section{References}

Abbott, A. (2001) "Time Matter," Chicago: University of Chicago Press.

Alavi, M., and Carlson, P. (1992) "A review of MIS research and disciplinary development," Journal of Management Information Systems 8 (4), pp. 45-62.

Alter, S. (2001) "Recognizing the relevance of IS research and broadening the appeal and applicability of future publications," Communications of the Association for Information Systems 6 (3), pp. 1-9.

Backhouse, J., Liebenau, J., and Land, F. (1991) "On the discipline of information systems," Journal of Information Systems 1 (1), pp. 19-27.

Banville, C., and Landry, M. (1989) "Can the field of MIS be disciplined?" Communications of the ACM 32 (1), pp. 48-60.

Barabasi, A. L., Albert, R., and Jeong, H. (1999) "Mean-field theory for scalefree random networks," Physica $A$. (272:1-2), pp. 173-187.

Barabasi, A. L., Jeong, H., Neda, Z., Ravasz, E., Schubert, A., and Vicsek, T. (2002) "Evolution of the social network of scientific collaborations," Physica A. 311 (3-4), pp. 590-614.

Barki, H., Rivard, S., and Talbot, J. (1988) "An Information Systems Keyword Classification Scheme," MIS Quarterly 12 (2), pp. 299-322.

Barki, H., Rivard, S., and Talbot, J. (1993) "An Information Systems Keyword Classification Scheme for IS Research literature: An Update," MIS Quarterly 17 (2), pp. 209-226.

Barkhi, R., and SD Sheetz (2001) "The State of Theoretical Diversity in Information Systems," Communications of the AIS 7 (6), pp. 1

Benbasat, I. (1989) "Laboratory Experiments in Information Systems with a Focus on Individuals: A Critical Appraisal," in I. Benbasat (ed.), The Information System Research Challenge: Experimental Research Methods (pp.
97-111). Boston, MA: Harvard Business School Press.

Benbasat, I., and Weber R. (1996) "Research Commentary: Rethinking 'Diversity' in Information Systems Research," Information Systems Research (7:4), pp. 389-399.

Benbasat, I., and Zmud, R.W. (1999) "Empirical research in information systems: The practice of relevance," MIS Quarterly 23 (1), pp. 3-16.

Benbasat, I., and Zmud, R. W. (2003) "The identity crisis within the IS discipline: Defining and communicating the discipline's core properties," MIS Quarterly 29 (2), pp. 183-194.

Bonacich, P.B. (1987), "Power and centrality: a family of measures," American Journal of Sociology 92 (5), pp. 11701182.

Borgatti, S. P. (1998) "What is social network analysis?," Retrieved from http://www.analytictech.com/networks/ whatis.htm

Borgatti, S. P., and Cross, R. (2003) "A relational view of information seeking and learning in social networks," Management Science 49 (4), pp. 432445.

Brandes, U., Raab, J., and Wagner, D. (2001) "Exploratory network visualization: Simultaneous display of actor status and connections," Journal of Social Structure 2 (4), pp. 1-28.

Burt, R. (1992) "Structural Holes: The Social Structure of Competition," Cambridge, MA: Harvard University Press.

Burt, R. S. (2002) "The Social Capital of Structural Holes," In M. F. Guillén, R. Collins, P. England, and M. Meyer (Eds.), The New Economic sociology: Developments in an Emerging Field. Russell Sage Foundation.

Cash, J.I., and Lawrence, P.R. (1989) "The Information Systems Research Challenge: Qualitative Research Methods," Boston, MA: Harvard Business School.

Checkland, P. B., and Howell, S. (1998) 
"Information, Systems and Information Systems: Making sense of the field," In W. John and UK. Sons (Eds).

Coleman, J.S. (1988) "Social capital in the creation of human capital," American Journal of Sociology 94, pp. 95-120.

Cooper, R.B. (1988) "Review of management information systems research: A management support emphasis," Information Processing and Management 24 (1), pp. 76-88.

Crane, D. (1972) "Invisible colleges: Diffusion of knowledge in scientific communities," Chicago, USA: University of Chicago Press.

Cross, R., Parker, A., Prusak, L., and Borgatti, S. P. (2001) "Knowing what we know: Supporting knowledge creation and sharing in social networks," Organizational Dynamics 30 (2), pp. 100-120.

Culnan, M. J. (1986) "The Intellectual Development of Management Information Systems, 1972-1982: A Co-Citation Analysis," Management Science 32 (2), pp. 156-172.

Culnan, M. J. (1987) "Mapping the intellectual structure of MIS, 1980-1985: A cocitation analysis," MIS Quarterly 11 (3), pp. 341-353.

Currie, Wendy, and Galliers, B. (1999) "Rethinking Management Information Systems," Oxford: Oxford University Press.

Daipha, P. (2001) "The intellectual and social organization of ASA 1990-1997," The American Sociologist 32 (3), pp. 73-90.

Dennis, A. R., Valacich, J. S., Fuller, M. A., and Schneider, C. (2006) "Research standards for promotion and tenure in information systems," MIS Quarterly 30 (1), pp. 1-12.

Epple, D., Argote, L., and Devadas, R. (1991) "Organizational learning curves: A method for investigating intra-plant transfer acquired through learning by doing," Organization Science 2 (1), pp. 58-70.

Farhoomand, A. F. (1987) "Scientific Progress Of Management Information
Systems," DataBase, 18 (4), pp. 4856.

Fleming, L., and Marx, M. (2006) "Managing Innovation in Small Worlds," Harvard Business School 48 (1), pp. 8-9.

Galliers, R. D. (1992) "Choosing information systems research approaches," In R. D. Galliers (Ed.), Information Systems Research: Issues, Methods and Practical Guidelines. Oxford: Blackwell Scientific.

Garguilo, M., and Rus, A. (2002) "Access and mobilization: Social capital and top management response to market shocks," Working paper, INSEAD.

Gargiulo, M. and Rus, A. (2001) "Access and Mobilization: Social Capital and Top Management Response to Market Shocks," Working paper, INSEAD.

Gillenson, M. L., and Stutz, J. D. (1991) "Academic issues in MIS: Journals and books," MIS Quarterly 15 (4), pp. 447-452.

Gould, R. (2002) "The Origins of Status Hierarchies: A Formal Theory and Empirical Test," American Journal of Sociology 107 (11), pp. 43-78.

Grover, V., Ayyagari, R., Gokhale, R., Lim, J., and Coffey, J. (2006) "A citation analysis of the evolution and state of information systems within a constellation of reference disciplines," Journal of the Association for Information Systems 7 (5), pp. 270325.

Hanneman, R. (1998) Introduction to social network. Retrieved from http://wizard.ucr.edu/ rhannema/netw orks/nettext.pdf

Hirscheim, R., Klein, H. K., and Lyytinen, K. (1995) "Information Systems Development and Data Modeling: Conceptual and Philosophical Foundations," Cambridge, UK: Cambridge University Press.

Hirscheim, R., and Klein, H. K. (2003) "Crisis in the IS field? A Critical refelection on the state of the discipline," Journal of the Association for Information Systems 4 (10), pp. 237-293.

Huang, H. H., and Hsu, J. (2005) "An 
evaluation of publication productivity in information systems: 1999 to $2003, "$ Communications of the Association for Information Systems 15, pp. 555564.

Huber, G.P. (1983) "Cognitive style as a basis for MIS and DSS designs: Much Ado about Nothing?," Management Science 29 (5), pp. 567-577.

Inkpen, A.C., and Tsang, E.W.K. (2005) "Social capital, Networks, and Knowledge Transfer," Academy of Management Review 30 (1), pp. 146165.

Ives, B., Hamilton, S., and Dasvis, G. (1980) "A framework for research in computer-based management information systems," Management Science 26 (9), pp. 910 - 934.

Katerattanakul, P., Han, B., and Hong, S. (2003) "Objective quality ranking of computing journals," Communications of the ACM 46 (10), pp. 111-114.

Katerattanakul, P., Han, B., and Rea, A. (2006) "IS information systems a reference discipline," Communications of the ACM 49 (5), pp. 114 - 118.

Keen, P.G.W. (1980) "MIS Research: Reference Disciplines and Cumulative Tradition," Proc. 1st International Conference on Information Systems, Philadelphia, Pennsylvania, pp. 9-18.

King, J., and Lyytinen, K. (2003) "When Grasp Exceeds Reach: Will Fortifying our Theoretical Core Save the Information Systems (IS) Field?," In T. Järvi and P. Reijonen (Eds.), People and Computers: Twenty-one Ways of Looking at Information Systems: Festschrift Celebrating Markku Nurminen's 60th Birthday, TUCS General Publication (pp. 143-165). Turku, Finland: Turku Centre for Computer Science, Finland.

Klein, H. K., and Myers, M. D. (1999) "A Set of Principles for Conducting and Evaluating Interpretive Field Studies in Information Systems," MIS Quarterly 23 (1), pp. 67-93.

Klein, G., Jiang, J.J., and Saunders C. (2006) "Leading the horse to water,"
Communications of the Association for Information Systems 18 (3), pp. 129.

Kraemer, K. L. (1991) "The information systems research challenge: Survey research methods," In J. Cash Jr. and J. F. Nunamaker Jr. (Eds.), The information systems research colloquium. Boston, MA: Harvard Business School Press,

Landry, M., and Banville, C. (1992) "A disciplined methodological pluralism for MIS research," Accounting, Management and Information Technologies 2 (2), pp. 77-97.

Lee, A. S., Liebenau, J., and DeGross, J. I. (Eds.) (1997) Information Systems and Qualitative Research. London: Chapman \& Hall.

Lowry, P. B., Romans, D., and Curtis, A. (2004) "Global journal prestige and supporting disciplines: A scientometric study of information systems journals," Journal of the Association for Information Systems 5 (2), pp. 2977.

Markus, M. L. (1997) "The Qualitative Difference in Information Systems Research and Practice," In Lee, A. S., Liebenau, J., and DeGross, J. I. (Eds.) (1997), Information Systems and Qualitative Research. London: Chapman \& Hall.

Mingers, J., and Stowell, F. (1997) "Information systems: an emerging discipline?," London: McGraw-Hill.

Mingers, J. (2001) "Combining IS Research Methods: Towards a Pluralist Methodology," Information Systems Research 12 (3), pp. 240-259.

Moody, J. (2004) "The structure of a social science collaboration network: Disciplinary cohesion from 1963 to 1999," American Sociological Review 69 (2), pp. 213-238.

Moody, J., McFarland, D., and Bender-deMoll, S. (2005) "Dynamic network visualization," The American Journal of Sociology 110 (4), pp. 1206-1208.

Mumford, E., Hirschheim, R., Fitzgerald, G., and Wood-Harper, T. (Eds) (1985) 
Research Methods in Information Systems, Proceedings of IFIP WG 8.2 Colloquium, Manchester, North Holland.

Nerur, S., Sikora, R., Mangalaraj, G. and Balijepaly, V. (2005) "Assessing the Relative Influence of Journals in a Citation Network," Communications of the ACM 48 (11), pp. 71 - 74.

Newman, M. E. J. (2000) "Models of the small world," J. Statistical Physics 101 (3-4), pp. 819-841.

Newman, M. E. J. (2001) "The structure of scientific collaboration networks," Proceedings of the National Academy of Sciences of the United States of America 98 (2), pp. 404-409.

Newman, M.E.J. (2004) "Who is the best connected scientists? A study of scientific coauthorship networks," Lecture Notes in Physics 650, pp. 337-370.

Nissen, H.F., Klein, H.K. and Hirschheim, R. (Eds) (1991) Information Systems Research: Contemporary Approaches \& Emergent Traditions, IFIP, Elsevier Science Publishers, B.V. Amsterdam.

Nonaka, I., and Takeuchi, H. (1995) "The Knowledge-Creating Company: How Japanese Companies Create the Dynamics of Innovation," UK, Oxford: Oxford University Press.

Oh, W., Choi, J.N., and Kim, K. (2006) "Coauthorship Dynamics and Knowledge Capital: The Patterns of Cross-Disciplinary Collaboration in Information systems Research," Journal of Management Information Systems 22 (3), pp. 265-292.

Orlikowski, W., and Baroudi, J. (1991) "Studying information technology in organizations: Research approaches and assumptions," Information Systems Research 2 (1), pp. 1-28.

Orlikowski, W.J., and lacono, C.S. (2001) "Research Commentary: Desperately Seeking the 'IT' in IT Research - A Call to Theorizing the IT Artifact," Information Systems Research 12 (2), pp. 121-134.

Padgett, J.F., and Ansell, C. K. (1993)
"Robust action and the rise of the Medici," American Journal of Sociology 98 (6), pp. 1259-1319.

Peffers, K., and Ya, T. (2003), "Identifying and evaluating the universe of outlets for information systems research: Ranking the journals," Journal of Information Technology Theory and Application 5 (1), pp. 63.

Poell, R. F., and Van der Krogt, F. J. (2003) "Learning strategies of workers in the knowledge-creating company," Human resource development international 6 (3), pp. 387-403.

Powell, W. W., White, D. R., Koput, K. W., and Owen-Smith, J. (2005), "Network dynamics and field evolution: The growth of interorganizational collaboration in the life sciences," The American Journal of Sociology 110 (4), pp. 1132-1107.

Prasad, S., and Tata, J. (2005) "Publication patterns concerning the role of teams/groups in the information systems literature from 1990 to 1999," Information \& Management, 42 (8), pp. 1137-1148.

Reagans, R., and McEvily, B. (2003) "Network structure and knowledge transfer: The effects of cohesion and range," Administrative Science Quarterly 48 (2), pp. 240-267.

Reagans R., and Zuckerman, E. W. (2001) "Networks, diversity, and productivity: The social capital of corporate R\&D teams," Organization Science 12 (4), pp. 502-517.

Robey, D. (1996) "Research commentary: Diversity in information systems research-Threat, promise, and responsibility," Information Systems Research 7 (4), pp. 400-408.

Saunders, C. (2005a) "Editor's comments: From the trenches: Thoughts on developmental reviewing," MIS Quarterly 29 (2), pp. iii-xii.

Saunders, C. (2005b), "Editors' comments: Looking for diamond cutters," MIS Quarterly 29 (1), pp. iii-vii.

Saunders, C. (2005c) "Isworld.Net journal 
rankings," $\quad$ Retrieved from http://www.isworld.org/csaunders/rank ings-0517.htm

Saunders, C. (2006) "Editor's comments: Necessary changes," MIS Quarterly 30 (1), pp. iii-vi.

Swanson, E. B., and Ramiller, N. (1993) "Information systems research thematics: Submissions to a new journal, 1987-1992," Information Systems Research 4 (4), pp. 299-330.

Tushman, M. L. (1977) "Special boundary roles in the innovation process," Administrative Science Quarterly 22 (4), pp. 587 - 605.

Valacich, J.S., Fuller, M.A., Schneider, C., and Dennis, A.R. (2006), "Publication opportunities in premier business outlets: How level is the playing field?" Information Systems Research 17 (2), pp. 107-125.

Vessey, I., Ramesh, V., and Glass, R. (2002) "Research in Information Systems: An Empirical Study of Diversity in the Discipline and Its Journals," Journal of Management Information Systems 19 (2), pp. 129-174.

Wade, M., Biehl, M., and Kim, H. (2006)
"Information Systems is not a reference discipline (and what we can do about it)," Journal of the Association for Information Systems 7 (5), pp. 247-269.

Watts, D.J. (1999), "Small World," Princeton, NJ: Princeton University Press.

Watts, D. J., and Strogatz, S. H. (1998) "Collective dynamics of 'small-world' networks," Nature 393 (6684), pp. 440-442.

Wellman, B. (1996) "For a social network analysis of computer networks: A sociological perspective on collaborative work and virtual community," Paper presented at the 1996 ACM SIGCPR/SIGMIS conference on Computer personnel research, Denver, Colorado, United States.

Westin, S., Roy, M., and Kim, C. K. (1994) "Cross-fertilization of knowledge: The case of MIS and its reference disciplines," Information Resources Management Journal archive 7 (2), pp. 24-34. 
Pacific Asia Journal of the Association for Information Systems, Vol. 1, Iss. 1 [2009], Art. 10 Management Information Systems Research Networks/Wang et al.

\section{Appendix A:}

A green node (hollow in $B \& W$ ) denotes the gatekeeper in its corresponding cluster and a red node (solid in $B \& W$ ) is a regular member in each cluster. For clarity on the networks, we do not plot clusters having fewer than 5 authors.

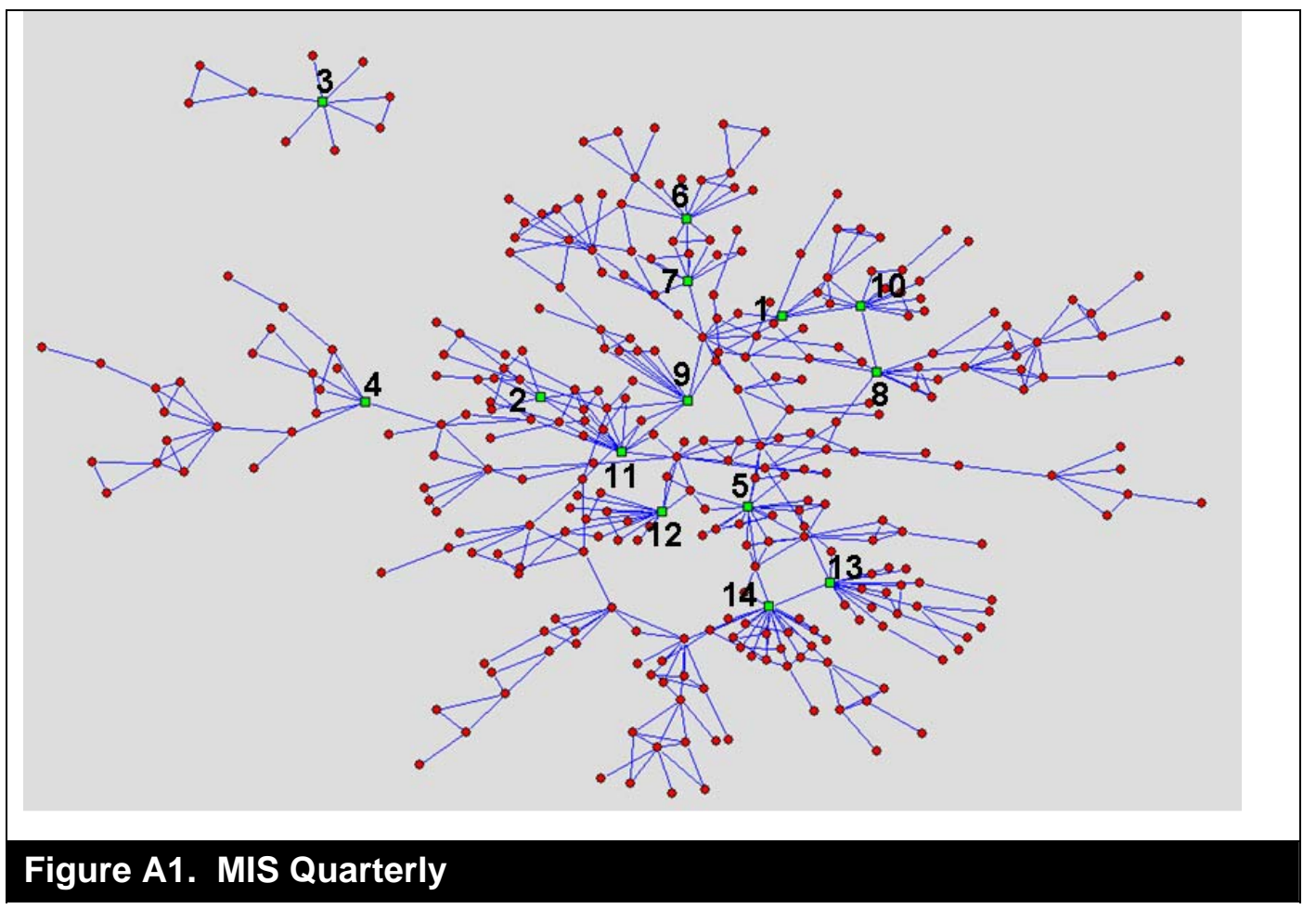




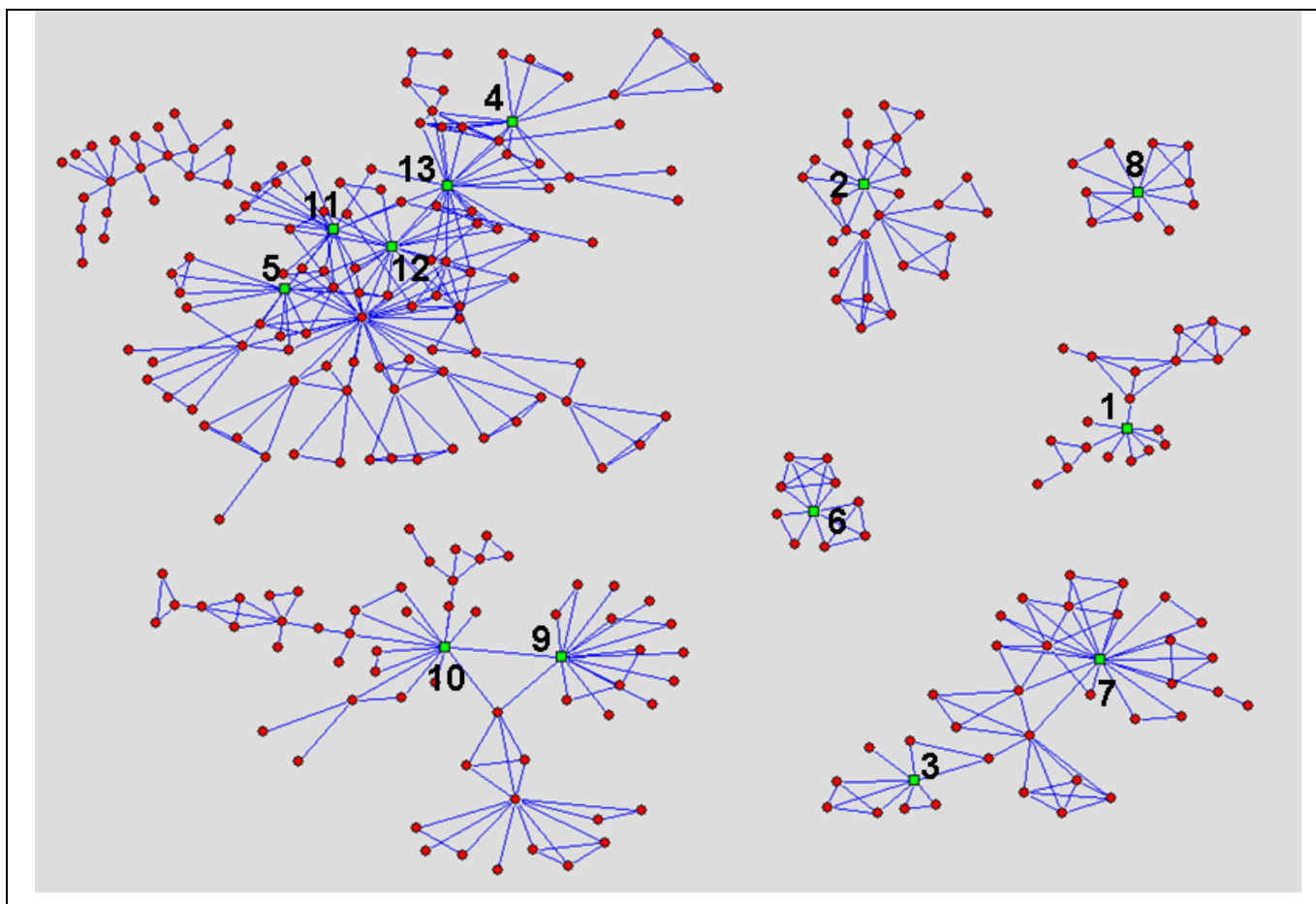

Figure A2. Journal of Management Information Systems

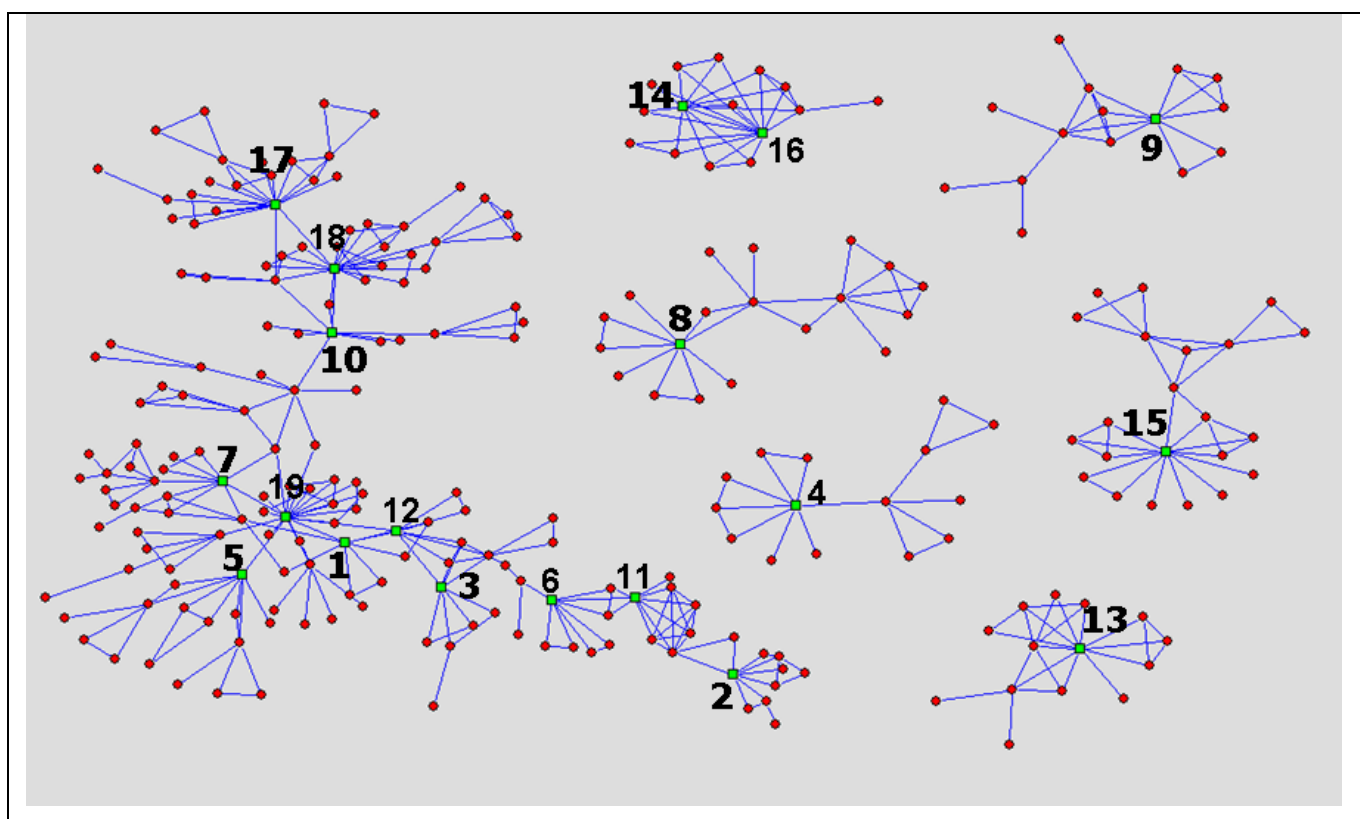

\section{Figure A3. Information \& Management}


Pacific Asia Journal of the Association for Information Systems, Vol. 1, Iss. 1 [2009], Art. 10 Management Information Systems Research Networks/Wang et al.

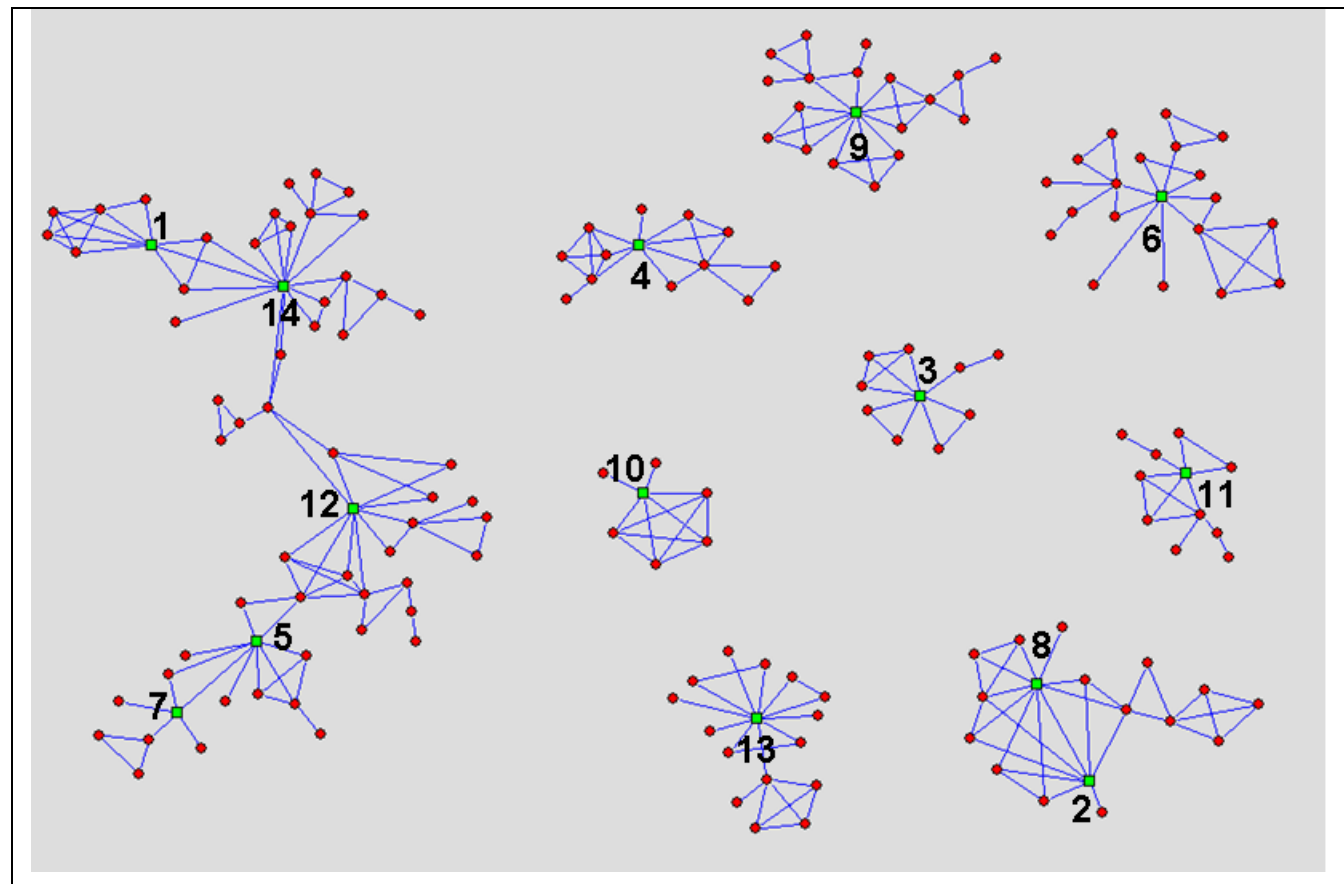

Figure A4. Information Systems Research

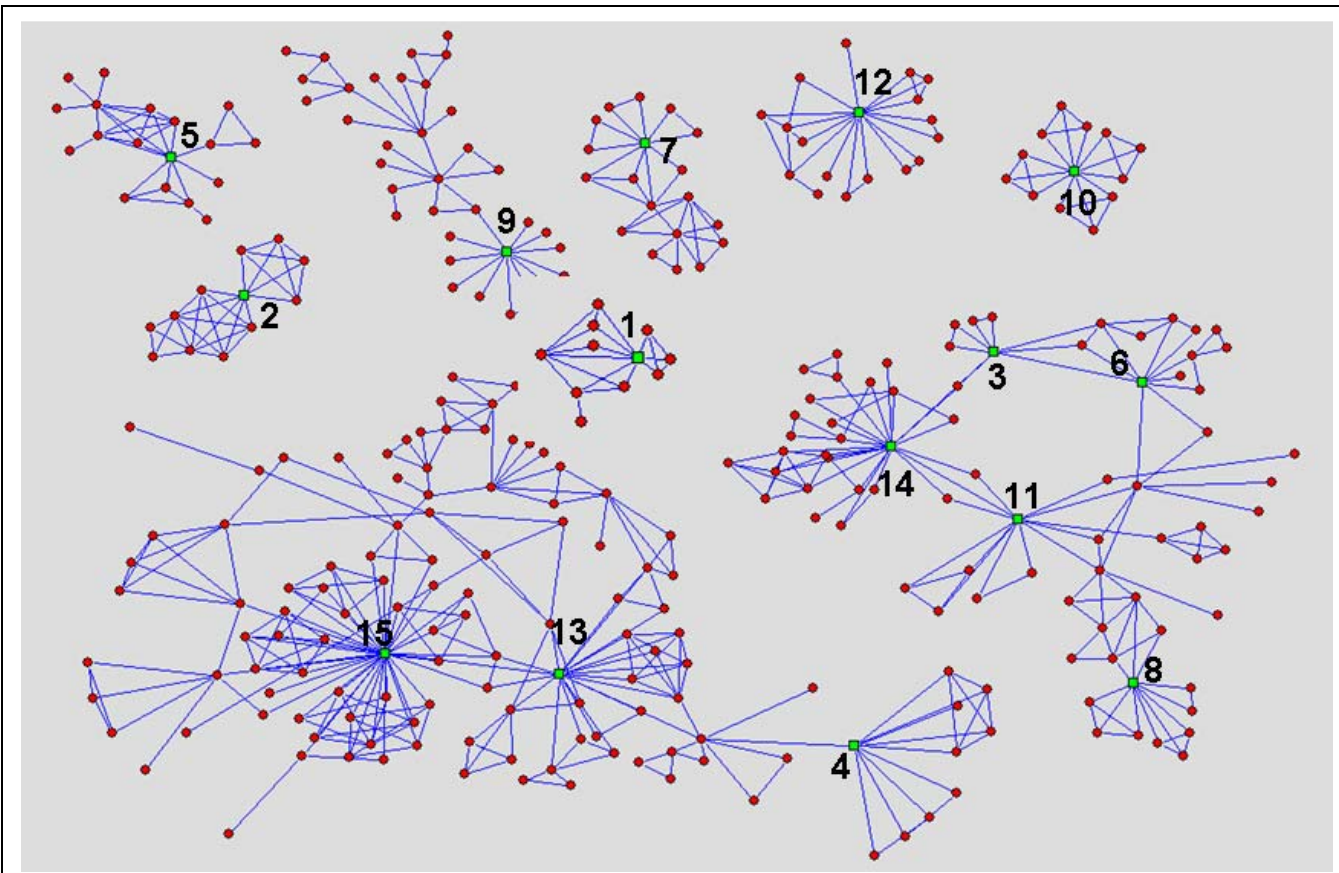

Figure A5. Decision Support Systems 
Wang et al:: Management Information Systems Research Networks: Creating and Sh

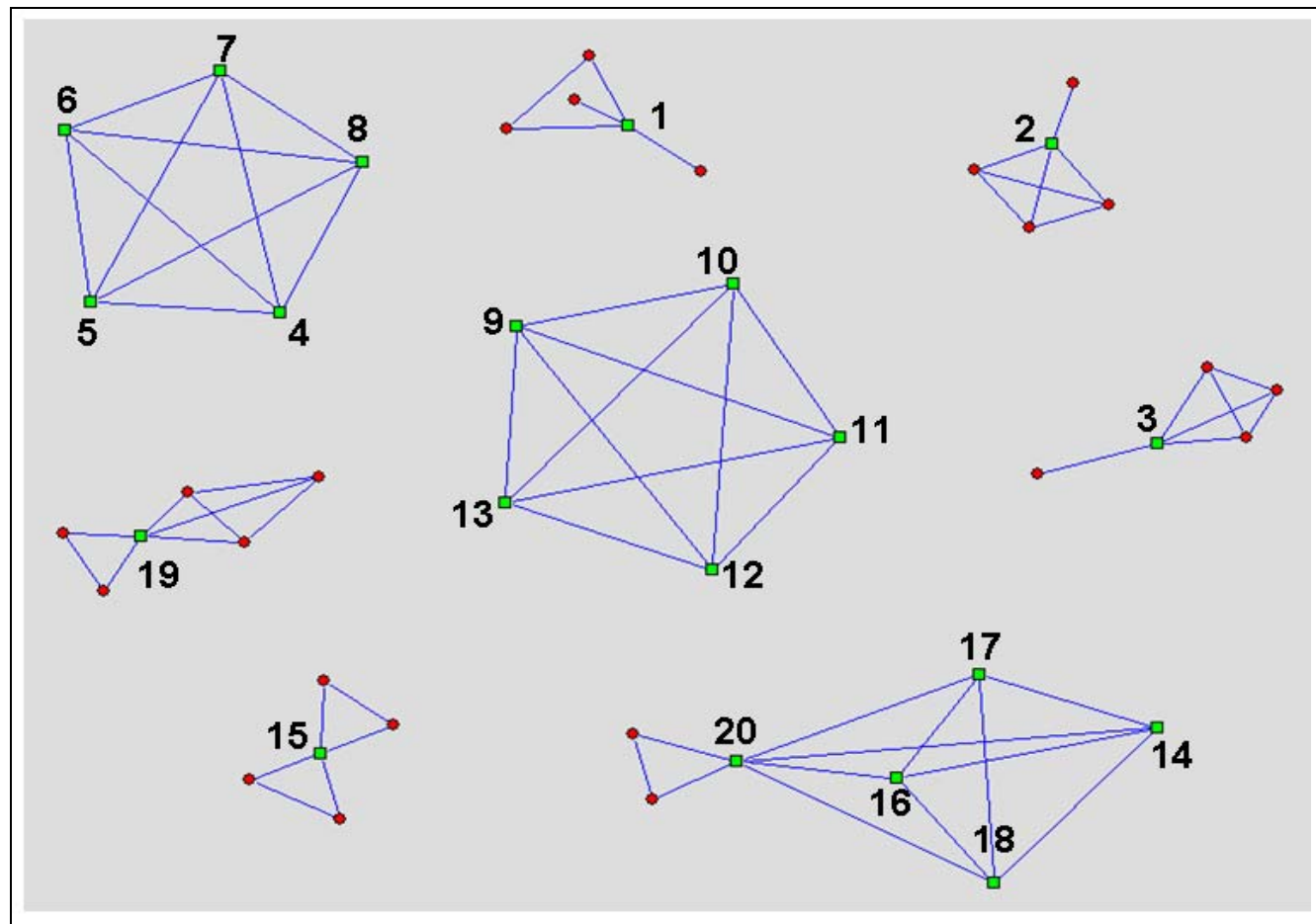

\section{Figure A6. Journal of the Association of Information Systems}

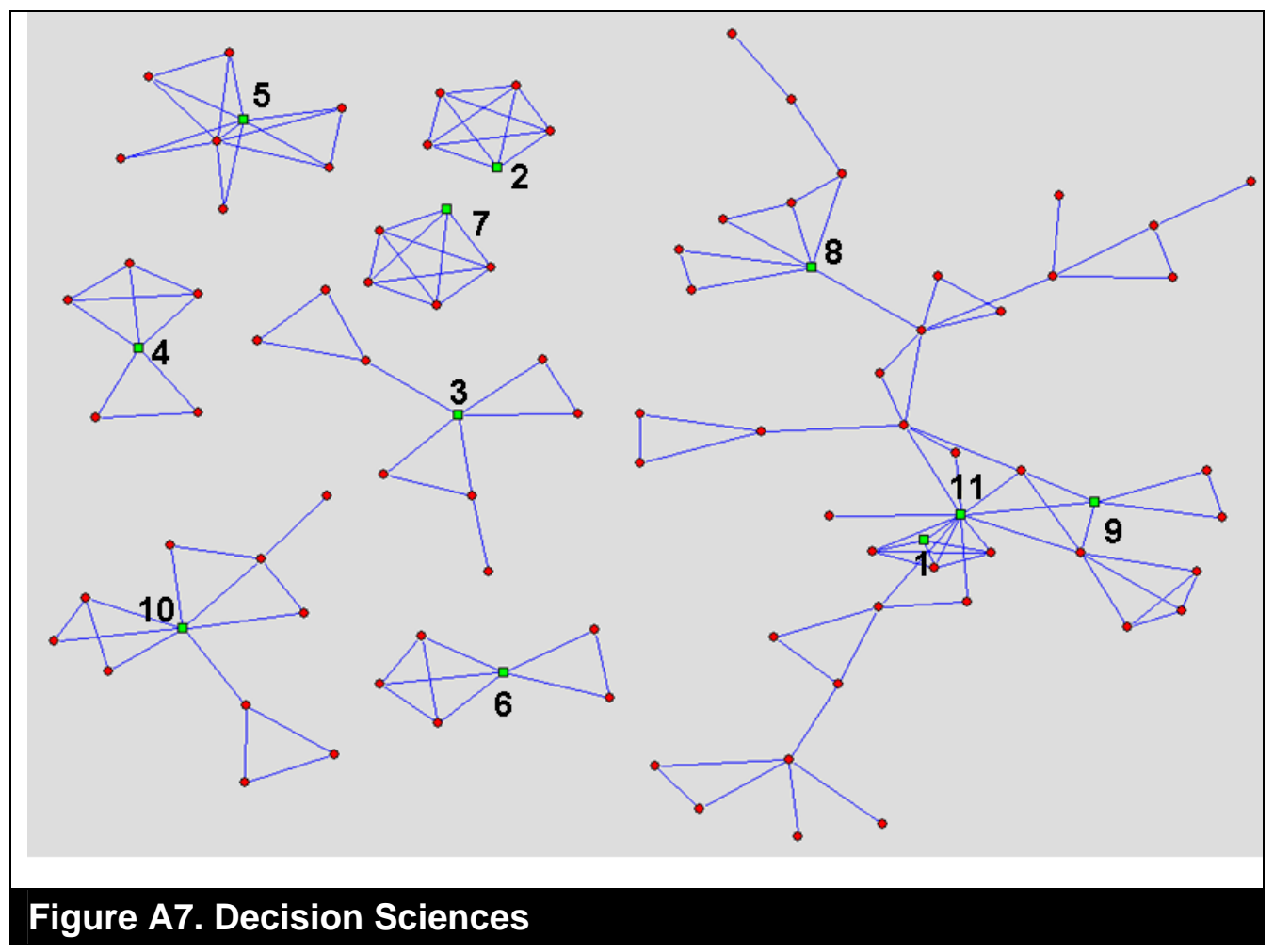




\section{About the Author}

Jyun-Cheng Wang is an Associate Professor of MIS in the Institute of Service Science at the National Tsing-Hua University, Taiwan, ROC. He holds a Ph.D. in Management of Information Systems from the University of Wisconsin-Madison. His research interests are focused on applying social network analysis for technology-mediated interactions and online social networks. He has published papers on such topics as online auctions, internet marketing, and virtual communities.

Dr. Gary Klein is the Couger Professor of Information Systems at the University of Colorado in Colorado Springs. He obtained his Ph.D. in Management Science from Purdue University. Before that time, he served with the company now known as Accenture in Kansas City and was director of the Information Systems Department for a regional financial institution. His research interests include project management, technology transfer, and mathematical modelling with over 140 academic publications in these areas. He teaches programming, project management, statistics, management science, and knowledge management courses. $\mathrm{He}$ is Director of Education for the American Society for the Advancement of Project Management, a Fellow of the Decision Sciences Institute, Vice Chair of Membership and Community Relations for the AIS SIG on IT Project Management, and an active member of the Institute of Electrical and Electronic Engineers, the Association for Computing Machinery, INFORMS, the Association of Information Systems, and the Project Management Institute.

Dr. James Jiang is Professor of Management Information Systems at the University of Central Florida. He obtained his Ph.D. in Information Systems at the University of Cincinnati. $\mathrm{He}$ is also the honorary Sun Yat-Sen Management Chair Professor of Information Management at National Sun Yat-Sen University, Taiwan,
2007-2010. He was the honorary Jin-Ding Chair Professor at National Central University, Taiwan, 2003-2005. His research interests include IS project management and IS service quality management. He has published over 130 academic articles in these areas in the journals such as Decision Sciences, Decision Support Systems, Journal of Management Information Systems, Communications of ACM, IEEE Transactions on Systems Men \& Cybernetics, IEEE Transactions on Engineering Management, Journal of AIS, European Journal of Information Systems, Information \& Management, Data Base, Journal of Systems \& Software, Information Resources Management Journal, and MIS Quarterly. Currently, he is an AE of MIS Quarterly and Information Resources Management Journal.

Dr Paul Cheney is Professor and Department Head of Management Information Systems at the University of Central Florida. He received his $\mathrm{PhD}$ in Management Information Systems from the University of Minnesota in 1977. He has taught at Texas Tech University, lowa State University, the University of Georgia, the University of South Florida, and most recently, at the University of Central Florida. His research has been primarily in the areas of managing information technology resources and he has published more then fifty articles and one textbook in the field of MIS. His articles have appeared in, among others, the MIS Quarterly, Academy of Management Journal, Journal of Management Information Systems, Information Systems Research, and Decision Sciences. He has supervised fourteen PhD dissertations and served on over fifty PhD committees. In addition, he has received numerous grants from private and public organizations. One of these was a \$2 million dollar grant from IBM in 1985 to support graduate MIS education. A similar grant was awarded by Solomon BrothersSmith Barney in 1993 for $\$ 1.8$ million dollars. 